\title{
Unraveling the driving forces in the self-assembly of monodisperse naphthalenediimide-oligodimethylsiloxane block molecules
}

Citation for published version (APA):

Berrocal, J. A., Zha, R. H., de Waal, B. F. M., Lugger, J. A. M., Lutz, M., \& Meijer, E. W. (2017). Unraveling the driving forces in the self-assembly of monodisperse naphthalenediimide-oligodimethylsiloxane block molecules. ACS Nano, 11(4), 3733-3741. https://doi.org/10.1021/acsnano.6b08380

DOI:

10.1021/acsnano.6b08380

Document status and date:

Published: 25/04/2017

Document Version:

Publisher's PDF, also known as Version of Record (includes final page, issue and volume numbers)

Please check the document version of this publication:

- A submitted manuscript is the version of the article upon submission and before peer-review. There can be important differences between the submitted version and the official published version of record. People interested in the research are advised to contact the author for the final version of the publication, or visit the $\mathrm{DOI}$ to the publisher's website.

- The final author version and the galley proof are versions of the publication after peer review.

- The final published version features the final layout of the paper including the volume, issue and page numbers.

Link to publication

\footnotetext{
General rights

- You may freely distribute the URL identifying the publication in the public portal. follow below link for the End User Agreement:

www.tue.nl/taverne

Take down policy

If you believe that this document breaches copyright please contact us at:

openaccess@tue.nl

providing details and we will investigate your claim.
}

Copyright and moral rights for the publications made accessible in the public portal are retained by the authors and/or other copyright owners and it is a condition of accessing publications that users recognise and abide by the legal requirements associated with these rights.

- Users may download and print one copy of any publication from the public portal for the purpose of private study or research.

- You may not further distribute the material or use it for any profit-making activity or commercial gain

If the publication is distributed under the terms of Article $25 \mathrm{fa}$ of the Dutch Copyright Act, indicated by the "Taverne" license above, please 


\title{
Unraveling the Driving Forces in the Self- Assembly of Monodisperse Naphthalenediimide-Oligodimethylsiloxane Block Molecules
}

José Augusto Berrocal, ${ }^{\dagger}$ R. Helen Zha, ${ }^{\dagger}$ Bas F. M. de Waal, ${ }^{\dagger}$ Jody A. M. Lugger, ${ }^{\dagger}$ Martin Lutz, $^{\ddagger}$ and E. W. Meijer*, ${ }^{*}(1)$

${ }^{\dagger}$ Institute for Complex Molecular Systems and Laboratory of Macromolecular and Organic Chemistry, Eindhoven University of Technology, 5600 MB Eindhoven, The Netherlands

"Crystal and Structural Chemistry, Bijvoet Center for Biomolecular Research, Utrecht University, $3584 \mathrm{CH}$ Utrecht, The Netherlands

\author{
Supporting Information
}

ABSTRACT: Block molecules belong to a rapidly growing research field in materials chemistry in which discrete macromolecular architectures bridge the gap between block copolymers (BCP) and liquid crystals (LCs). The merging of characteristics from both BCP and LCs is expected to result in exciting breakthroughs, such as the discovery of unexpected morphologies or significant shrinking of domain spacings in materials that possess the high definition of organic molecules and the processability of polymers. Here we report the bulk self-assembly of two families of monodisperse block molecules comprised of

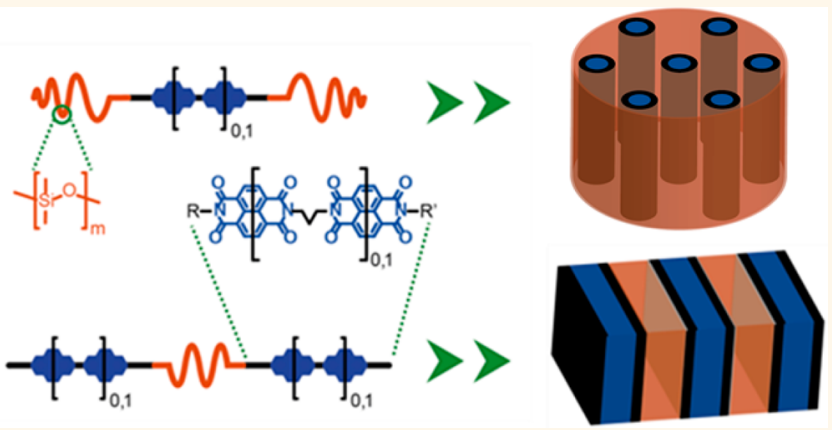
naphthalenediimides (NDIs) and oligodimethylsiloxanes (ODMS). These materials are characterized by waxy texture, strong long-range order, and very low mobility, typical properties of conformationally disordered crystals. Our investigation unambiguously reveals that thermodynamic immiscibility and crystallization direct the self-assembly of ODMS-based block molecules. We show that a synergy of high incompatibility between the blocks and crystallization of the NDIs causes nanophase separation, giving access to hexagonally packed columnar $\left(\mathrm{Col}_{h}\right)$ and lamellar (LAM) morphologies with sub-10 $\mathrm{nm}$ periodicities. The domain spacings can be tuned by mixing molecules with different ODMS lengths and the same number of NDIs, introducing an additional layer of control. X-ray scattering experiments reveal macrophase separation whenever this constitutional bias is not observed. Finally, we highlight our "ingredient approach" to obtain perfect order in sub-10 nm structured materials with a simple strategy built on a crystalline "hard" moiety and an incompatible "soft" ODMS partner. Following this simple rule, our recipe can be extended to a number of systems.

KEYWORDS: block molecules, nanophase separation, nanostructured materials, monodispersity, oligodimethylsiloxanes, conformationally disordered crystals, plastic crystals

r he establishment of molecular self-assembly as a discrete field at the interface between chemistry and materials science ${ }^{1}$ continues to push the forefront of technology $y^{2}$ and creates exciting challenges in molecular synthesis. $^{3-5}$ One of the most important goals in this field is to control the nanoscopic structure of materials through a bottom-up approach, ${ }^{1,3}$ ultimately leading to the miniaturization of domain spacings $\left(L_{0}\right)$. Achievement of this fundamental objective is expected to lead to outstanding technological breakthroughs, such as the constancy in pursuing Moore's Law ${ }^{6,7}$ — currently in a critical scenario-or the generation of a class of materials with exciting properties. In these respects, the recent discovery of block molecules ${ }^{8-10}$ has emerged as a frontier in the chemistry of materials. In block molecules well-established concepts from block copolymers (BCPs) $)^{11-14}$ and liquid crystals (LCs) $)^{15,16}$ are merged and chemically translated into perfectly defined macromolecular architectures comprised of two or more heterogeneous components. $^{8,10}$ The strength of this combination is the

Received: December 14, 2016

Accepted: April 5, 2017

Published: April 5, 2017 
opportunity to improve the characteristics of both BCPs and LCs by minimizing $L_{0}$ by up to $1-2 \mathrm{~nm}$, discovering unexpected morphologies, and blending the versatility of mechanical properties/processability of polymers with the high definition of discrete organic molecules. Consequently, many research groups have started to explore these monodisperse macromolecular architectures at the interface between BCPs and LCs, stimulating a discussion in the scientific community that will certainly be witnessed by a number of publications in the upcoming future. It is implicit that the fundamental understanding of the self-assembly of block molecules is necessary to fully exploit their potential for applications.

The nanophase separation of block copolymers has been extensively studied both experimentally ${ }^{17,18}$ and theoretically ${ }^{19-21}$ and the morphologies generated have been rationalized in terms of volume fraction $(f)$, degree of polymerization $(N)$, and incompatibility between the blocks $(\chi)$ as a result of the interplay between enthalpic and entropic forces to minimize interfacial energy. Domain spacings that scale proportionally to $\chi^{1 / 6} \mathrm{~N}^{2 / 3}$ are achieved in the strong segregation regime. The conclusion that high $\chi /$ low $N$ BCPs may represent a solution to smaller feature sizes $(<10 \mathrm{~nm})$ is logical and has been underlined in a recent perspective. ${ }^{22} \mathrm{~A}$ plausible strategy to achieve ordered structure formation with lower $N$ is the use of polydimethylsiloxane (PDMS), ${ }^{23,24}$ because of its high $\chi$ value and etch contrast with a variety of organic components. ${ }^{25}$ Recently, we have shown that very small features can be obtained with dimethylsiloxane-lactic acid diblock co-oligomers, ${ }^{26}$ while perfect dispersity helped to push the boundaries of phase separation to $L_{0}$ as small as $6.8 \mathrm{~nm} .^{27}$

Further lowering of the molar mass of the self-assembling architecture brings us to the fields of liquid crystals (LCs) ${ }^{28,15}$ plastic crystals (PCs) ${ }^{29-31}$ and conformationally disordered crystals (CDCs). ${ }^{32,33}$ In contrast to BCPs, no phase separation is mandatory in LCs, PCs and CDCs, since molecular shape and directionality of intermolecular interactions between crystalline moieties determine the type of morphology regardless of molecular composition. For example, discotic LCs most often assume columnar morphologies, ${ }^{34,35}$ whereas calamitic LCs give rise to nematic or smectic phases, ${ }^{28}$ with sizes in the range of few nanometers (matching with molecular size). ${ }^{36}$ The major differences between LCs and PCs/CDCs consist in long-range order and flowing ability, with PCs/CDCs being significantly more ordered as a consequence of lower mobility. Although many books and reviews have been dedicated to PCs and CDCs, ${ }^{29-33}$ the scientific community is still waiting for an official definition of both types of materials from the International Union of Pure and Applied Chemistry (IUPAC). This contrasts starkly with the state of the art in the field of LCs, for which a convention has been reached. ${ }^{37}$

As previously stated, block molecules ${ }^{8-10}$ merge the discrete design of LCs/PCs/CDCs with the high incompatibility/ heterogeneity of BCP. These architectures are based on a rodcoil motif, where "hard" aromatic blocks are connected to "soft", flexible chains. They are inspired by rod-coil block copolymers $^{38-40}$ and represent a significant step toward the "miniaturization" of molecular design and $L_{0}$ thanks to the difference in stiffness between the blocks. The first examples were based on well-defined oligo(ethylene glycol) derivatives, exploiting an amphiphilic design that allowed for self-assembly in water or organic solvents. ${ }^{9}$ Very few systems exploring alternatives to oligo(ethylene glycol) chains have been reported since then. ${ }^{41-45}$ Recent progress in the synthesis of discrete oligodimethylsiloxanes (ODMS) in our group ${ }^{46,27}$ has led to the generation of block molecules without the constriction of amphiphilicity. These structures are fully hydrophobic and, like BCPs, do not require a solvent as a driving force for aggregation and interface minimization, as recently shown with UreidoPyrimidinone (UPy) end-capped ODMS. ${ }^{46}$ While the UPy-based ODMS follow a BCP-like self-assembly behavior, the benzylprotected derivatives always exhibit a lamellar organization regardless of molecular composition. ${ }^{46}$ It was hypothesized that crystallization of the benzyl-protected UPy moiety in the UPyODMS conjugates was the reason for the generation of the lamellar morphologies. If such hypothesis was confirmed, these lamellar architectures could be defined as exfoliated crystalline layers.

In this paper we report the self-assembly in bulk of two families of discrete block molecules consisting of ODMS functionalized with naphthalenediimides (NDIs), ${ }^{47}$ crystalline aromatic moieties. ${ }^{48}$ The combination of NDIs and siloxanes in discrete systems has already been investigated by others, ${ }^{49-51}$ but none of these studies pushed the boundaries of molecular definition to an intermediate regime between small molecules and polymeric systems. The fully extended chemical structures of monodisperse Si15- $\mathrm{NDI}_{2}-\mathrm{Si} 15$ and $\mathrm{NDI}_{2}-\mathrm{Si} 16-\mathrm{NDI}_{2}$ are shown in Chart 1 as examples. A more compact and general

Chart 1. Pictorial Representations and Fully Extended Chemical Structures of Si15-NDI $-\mathrm{Ni}_{2} 5$ and $\mathrm{NDI}_{2}-\mathrm{Si16}-\mathrm{NDI}_{2}$
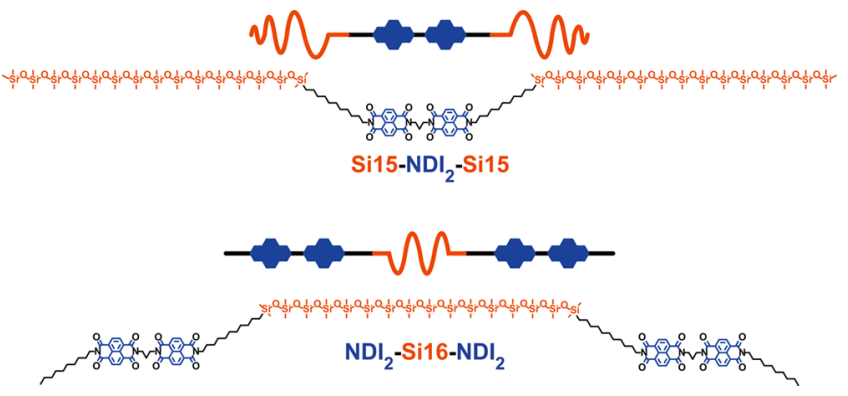

representation of $\mathbf{S i - N D I} / \mathrm{NDI}_{2}-\mathrm{Si}$ (family $\mathbf{1}$ ) and $\mathrm{NDI} / \mathrm{NDI}_{2}-$ $\mathrm{Si}-\mathrm{NDI} / \mathrm{NDI}_{2}$ (family 2), series of compounds in which one and two NDIs (NDI and $\mathrm{NDI}_{2}$, respectively) are coupled to three different lengths of perfectly defined ODMS, namely Si7, Si15, and Si23 for family 1 , and Si8, Si16, and Si24 for family 2 , is reported in Figure 1. Compared to our previous ODMSbased systems, ${ }^{52,27,46}$ we introduce modularity in the chemical design of the crystalline block. This choice finally unravels the driving forces controlling the self-assembly of the block molecules and highlights the occurrence of crystallization of the hard block, a process that was only hypothesized in one ${ }^{46}$ of the previous ODMS-based systems. ${ }^{27,52}$

We find that the block molecules possess characteristics similar to those of conformationally disordered crystals ${ }^{59}$ and self-assemble into sub-10 nm periodic morphologies caused by a synergy between NDI crystallization and phase separation. Our claims are supported by a number of experimental evidence that consistently point to the formation of perfectly crystallized NDI domains in the bulk of the NDI-ODMS conjugates, furnishing a general understanding of the selfassembly of ODMS-based block molecules. We unambiguously confirm the occurrence of crystallization in the NDI-ODMS conjugates with a number of mixing experiments, in which the 


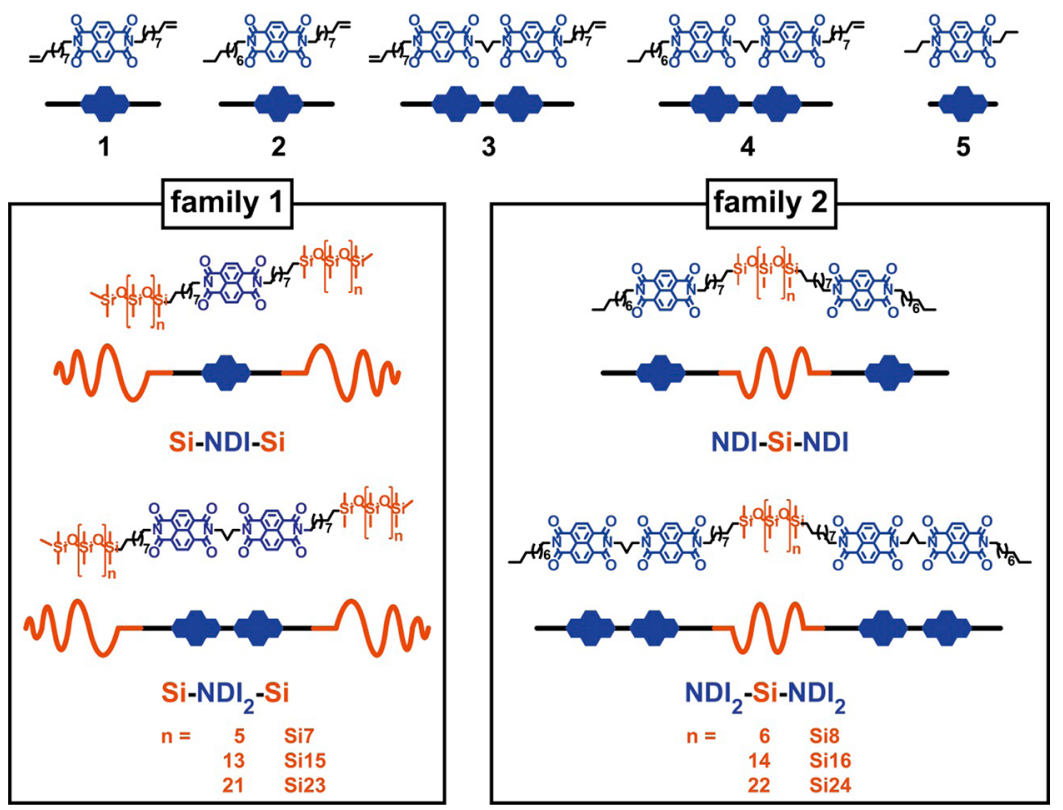

Figure 1. Chemical structures and pictorial representations of synthesized NDIs and families of NDI-ODMS conjugates.

periodicities of the nanostructures obtained can be easily tuned by mixing block molecules with the exact same number of NDIs in the hard block but different lengths of ODMS in the soft block. Macrophase separation occurs whenever this constitutional bias is not respected.

\section{RESULTS AND DISCUSSION}

Synthesis. The synthesis of all NDIs and NDI-ODMS conjugates was performed starting from commercially available chemicals and the discrete ODMS, which were prepared in a stepwise fashion previously published. ${ }^{27,46}$ The preparation of

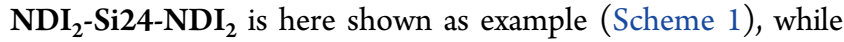
all synthetic procedures and molecular characterization of

Scheme 1. Synthetic Route for the Preparation of $\mathrm{NDI}_{2}-\mathrm{Si} 24-$ $\mathrm{NDI}_{2}$

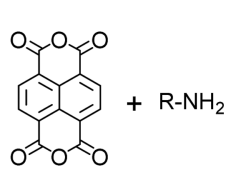

NDA
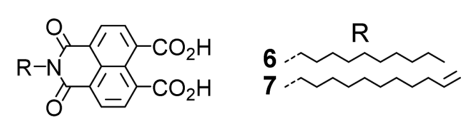

6,7

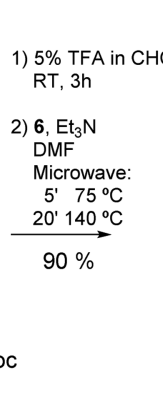

8

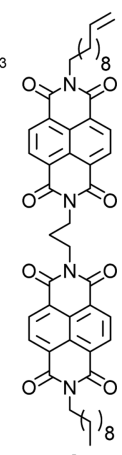

4 compounds are fully described in Supporting Information (SI). Naphthalenemonoimides (NMIs) 6 and 7 were obtained in high yields (68\%) from commercially available 1,4,5,8naphthalene tetracarboxylic dianhydride (NDA), n-decylamine and 10 -undecen-1-amine ${ }^{53}$ via optimization of a previously reported microwave assisted protocol. ${ }^{54}$ Microwave assisted condensation of 7 with $N$-(tert-Butoxycarbonyl)-1,3-diaminopropane afforded 8 in excellent yields (95\%). Trifluoroacetic acid (TFA)-induced Boc group removal from $\mathbf{8}$, followed by microwave reaction with 6 in the presence of excess triethylamine yielded 4 (90\% yield), in which two NDIs are connected via a three methylene linker. Finally, Pt-catalyzed hydrosilylation between 4 and $\mathbf{H}-\mathrm{Si} 24-\mathrm{H}$ at $70{ }^{\circ} \mathrm{C}$ in toluene

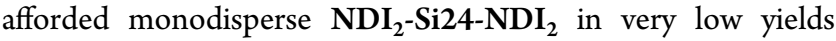
(3\%), probably due to the low solubility of 4 in the reaction medium that facilitated the occurrence of well-known side processes of hydrosilylations. ${ }^{55}$

Thermal Behavior and Morphology of the Materials. While NDIs 1-4 (Figure 1) are crystalline solids and the ODMS are liquid, ${ }^{27,46}$ all NDI-ODMS conjugates show a waxy consistency. This simple textural observation clearly suggests that the intermolecular interactions of the crystalline "hard" NDI block prevail over the "soft" and liquid nature of the ODMS. Further indications of these interactions were obtained when the thermal behavior of reference NDIs 1-4 and NDIODMS conjugates was studied with Differential Scanning Calorimetry (DSC) (Table 1, Figures S88-S98). The high degree of crystallinity of $\mathbf{1}$ and $\mathbf{2}$ is documented by the sharp transitions with typical enthalpic variations associated with melting/crystallization processes ${ }^{56}\left(\Delta H_{1}\right.$ and $\Delta H_{2}$, respectively) upon heating and cooling (Table 1 ). As expected, very similar values are obtained for $\mathbf{1}$ and $\mathbf{2}$. The introduction of the second NDI unit in 3 and 4, instead, results in the absence of phase transitions upon heating the samples up to $250^{\circ} \mathrm{C}$, which highlights a remarkable increase in thermal stability (Table 1 ).

The presence of the ODMS chains in the NDI-ODMS block molecules lowers the transition temperatures $\left(T_{1}\right.$ and $T_{2}$ upon heating and cooling, respectively) of the reference NDIs, while enthalpic energy is generally preserved. The lower $T_{1} / T_{2}$ values 
Table 1. Transition Temperatures and Associated Enthalpic Variations of Reference Compounds 1-4 and NDI-ODMS Conjugates Obtained with DSC Measurements ${ }^{a}$

\begin{tabular}{|c|c|c|c|c|}
\hline compound & $T_{1}^{b}\left({ }^{\circ} \mathrm{C}\right)$ & $\Delta H_{1}(\mathrm{~kJ} / \mathrm{mol})$ & $T_{2}^{c}\left({ }^{\circ} \mathrm{C}\right)$ & $\Delta H_{2}(\mathrm{~kJ} / \mathrm{mol})$ \\
\hline 1 & 150.4 & 21.5 & 143.4 & 22.8 \\
\hline 2 & 155.8 & 20.5 & 140.2 & 20.9 \\
\hline 3 & n.o. & - & n.o. & - \\
\hline 4 & n.o. & - & n.o. & - \\
\hline Si7-NDI-Si7 & 45.4 & 9.5 & 37.7 & 21.5 \\
\hline $\mathrm{Si} 7-\mathrm{NDI}_{2}-\mathrm{Si} 7$ & 211.3 & 32.1 & 205.5 & 33.4 \\
\hline Si15-NDI-Si15 & 28.1 & 19.8 & 22.4 & 16.2 \\
\hline Si15-NDI ${ }_{2}-\mathrm{Si} 15$ & 190.9 & 23.9 & 185.7 & 33.9 \\
\hline Si23-NDI-Si23 & 17.8 & 9.8 & 13.0 & 7.8 \\
\hline $\mathrm{Si} 23-\mathrm{NDI}_{2}-\mathrm{Si} 23$ & 180 & 21.8 & 166.8 & 22.2 \\
\hline NDI-Si8-NDI & 143.6 & 26.5 & 130 & 26.2 \\
\hline $\mathrm{NDI}_{2}-\mathrm{Si} 8-\mathrm{NDI}_{2}$ & n.o. & - & n.o. & - \\
\hline NDI-Si16-NDI & 114.4 & 25.4 & 103.5 & 36.1 \\
\hline $\mathrm{NDI}_{2}-\mathrm{Si16}-\mathrm{NDI}_{2}$ & n.o. & - & n.o. & - \\
\hline NDI-Si24-NDI & 116.8 & 44 & 116.67 & 55.2 \\
\hline $\mathrm{NDI}_{2}-\mathrm{Si} 24-\mathrm{NDI}_{2}$ & n.o. & - & n.o. & - \\
\hline
\end{tabular}

${ }^{a}$ All DSC data were collected during the second heating and cooling run. ${ }^{b} T_{1}$ is the transition temperature measured during heating. ${ }^{c} T_{2}$ is the transition temperature measured during cooling. Heating and cooling rate was $10^{\circ} \mathrm{C} / \mathrm{min}$ n.o. = not observed.

can be explained with an increasing presence of the liquid-like block in the molecular architecture. The functionalization with the ODMS allows to measure thermal transitions of block molecules comprising two NDIs in total, such as $\mathbf{S i - N D I}-\mathbf{S i}$ and NDI-Si-NDI conjugates (Figure 2 and Table 1). Featureless DSC traces are found with $\mathrm{NDI}_{2}-\mathbf{S i}-\mathrm{NDI}_{2}$ block molecules (Table 1). Enthalpic variations above or in the range of $15-20 \mathrm{~kJ} / \mathrm{mol}$, typical for crystallization upon cooling, ${ }^{56}$ are consistently observed for $\Delta H_{2}$ values in Table 1 . Such
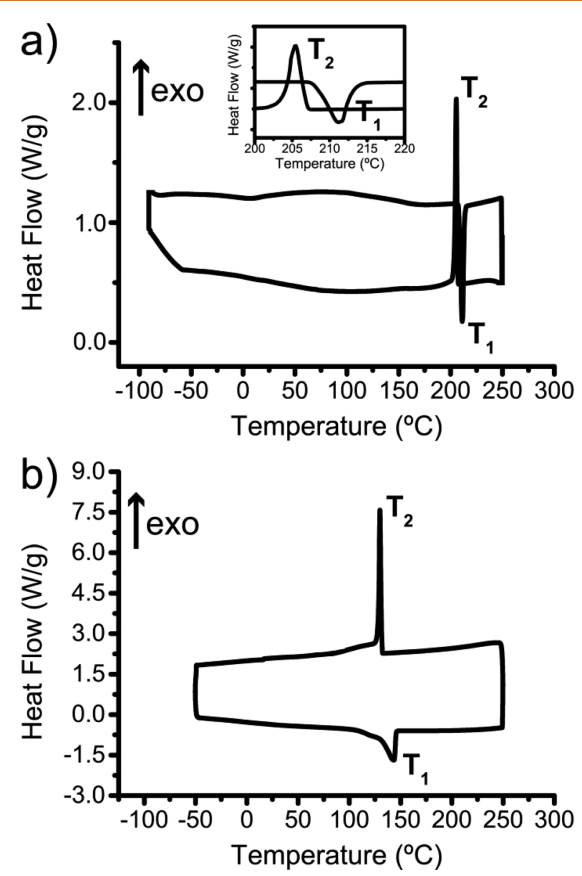

Figure 2. DSC traces (exo up) of (a) Si7-NDI $-\mathrm{Si} 7$ and (b) NDISi8-NDI with transition temperatures measured upon heating and cooling ( $T_{1}$ and $T_{2}$, respectively). The inset in (a) is a magnification of the two transitions of $\mathrm{Si7}-\mathrm{NDI}_{2}-\mathrm{Si} 7$ in the $200-220{ }^{\circ} \mathrm{C}$ range. consistency suggests the occurrence of NDI melting/crystallization processes within the NDI-ODMS conjugates. Interestingly, the highest enthalpic energies upon cooling are measured with block-molecules comprised of two NDIs in total.

The crystallinity of reference compounds and NDIs within the block molecules was also strongly suggested by Polarized Optical Microscopy (POM). Under crossed polarizers, upon cooling from the isotropic melt at a rate of $10{ }^{\circ} \mathrm{C} / \mathrm{min}$, birefringent, nonflowing textures were observed for $\mathbf{1}$ and $\mathbf{3}$ (in agreement with DSC measurements, melting of $\mathbf{3}$ was observed around $340{ }^{\circ} \mathrm{C}$ with POM) (Figure S99). Similarly, the block molecules showed birefringent, nonflowing textures, indicating long-range order. The block molecules of family 1 always gave high-contrast, granular textures as shown in the POM micrograph of Si15-NDI-Si15 in Figure 3a (other POM a)
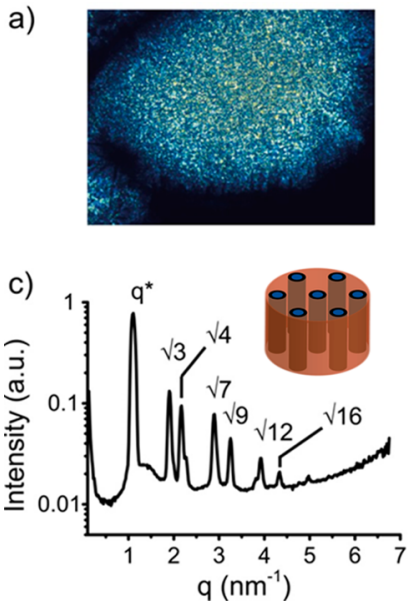

b)
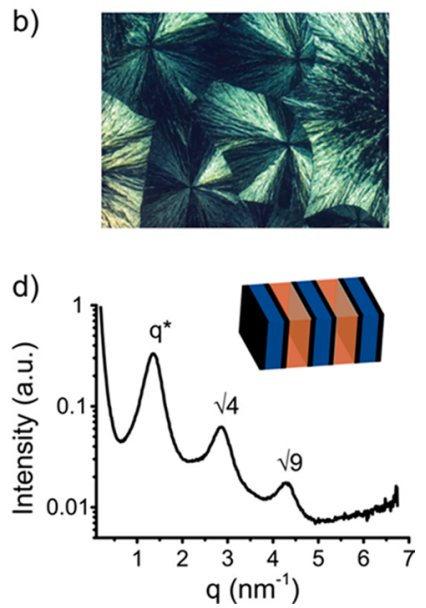

Figure 3. POM micrographs, under crossed polarizers, obtained upon slow cooling from the isotropic melt of (a) Si15-NDI-Si15 and (b) NDI-Si8-NDI showing granular and spherulitic textures, respectively. MAXS profiles of (c) Si15-NDI-Si15 and (d) NDI-Si8NDI showing indexed reflections of $\mathrm{Col}_{h}$ and LAM morphologies, respectively. Intensity is given in arbitraty units.

micrographs in Figure S99). The compounds of family 2 showed low-contrast, undefined, birefrigent textures in most cases (Figure S99), with the only exception of NDI-Si8-NDI, for which spherulitic textures were observed as a consequence of the very high crystallinity of this compound (Figure $3 \mathrm{~b}$ ). The low birefringence of almost all compounds of family 2 was most likely due to homeotropic alignment, instead. In conclusion, the birefringence of the block molecules is in agreement with the crystallization/melting processes suggested by DSC, and can be explained by the optical anisotropy arising from periodic crystalline domains (NDI block) of one refractive index nanophase separating from a matrix of a second refractive index (ODMS block).

To gain further insights into the long-range order of both families of block molecules, Medium Angle X-ray Scattering (MAXS) experiments were carried out. The block molecules were spread on mica substrates and annealed by slow cooling from isotropic melt. For samples with no thermal transitions by DSC, the mica samples were annealed at $300{ }^{\circ} \mathrm{C}$ for $30 \mathrm{~min}$ prior to measurement. Morphologies and domain spacings $\left(L_{0}\right)$ of all NDI-ODMS conjugates are summarized in Table 2 and Table S1 (MAXS profiles at SI pages S102-S113), with $L_{0}$ being the lattice parameter(s) of morphologies with hexagonal $\left(\mathrm{Col}_{\mathrm{h}}\right)$ and columnar oblique $\left(\mathrm{Col}_{\mathrm{ob}}\right)$ packing, and the bilayer 
Table 2. Domain Spacings $\left(L_{0}\right)$ and Phase Characterizations of NDI-ODMS Conjugates of Family 1 and 2

\begin{tabular}{|c|c|c|}
\hline compound & $L_{0}(\mathrm{~nm})^{a}$ & phase \\
\hline Si7-NDI-Si7 & $9.3(\mathrm{~A}), 2.9(\mathrm{~B}), 86.9^{\circ}(\gamma)$ & $\mathrm{Col}_{\mathrm{ob}}$ \\
\hline $\mathrm{Si} 7-\mathrm{NDI}_{2}-\mathrm{Si} 7$ & 6.1 & $\mathrm{Col}_{\mathrm{h}}$ \\
\hline Si15-NDI-Si15 & 6.5 & $\mathrm{Col}_{\mathrm{h}}$ \\
\hline Si15-NDI $2-S i 15$ & 7.4 & $\mathrm{Col}_{\mathrm{h}}$ \\
\hline Si23-NDI-Si23 & $7.8(\mathrm{~A}), 6.8(\mathrm{~B}), 80^{\circ}(\gamma)$ & $\mathrm{Col}_{\mathrm{ob}}{ }^{b}$ \\
\hline $\mathrm{Si} 23-\mathrm{NDI}_{2}-\mathrm{Si} 23$ & 8.8 & $\mathrm{Col}_{h}$ \\
\hline NDI-Si8-NDI & 4.4 & LAM \\
\hline $\mathrm{NDI}_{2}-\mathrm{Si} 8-\mathrm{NDI}_{2}$ & 5.2 & LAM \\
\hline NDI-Si16-NDI & 5.7 & LAM \\
\hline $\mathrm{NDI}_{2}-\mathrm{Si16}-\mathrm{NDI}_{2}$ & 6.3 & $\mathrm{LAM}^{c}$ \\
\hline NDI-Si24-NDI & 6.9 & $\mathrm{LAM}^{c}$ \\
\hline $\mathrm{NDI}_{2}-\mathrm{Si} 24-\mathrm{NDI}_{2}$ & 7.2 & $\mathrm{LAM}^{c}$ \\
\hline
\end{tabular}

${ }^{a} L_{0}$ is the lattice parameter(s) in $\mathrm{Col}_{\mathrm{h}}$ and $\mathrm{Col}_{\mathrm{ob}}$ and the bilayer thickness in LAM. ${ }^{b}$ Measured at $5{ }^{\circ} \mathrm{C}$. ${ }^{c}$ Samples annealed for $30 \mathrm{~min}$ at $300{ }^{\circ} \mathrm{C}$.

thickness in lamellar morphologies (LAM). MAXS profiles of Si15-NDI-Si15 and NDI-Si8-NDI are shown as examples in Figure $3 \mathrm{c}$ and $3 \mathrm{~d}$, respectively. Scattering patterns characterized by a number of sharp Bragg peaks were recorded for both series of conjugates, confirming the long-range order visualized with POM. Conjugates of family $\mathbf{1}$ always gave clear scattering patterns indicating $\mathrm{Col}_{\mathrm{h}}$ columnar morphologies, with the only exception of Si7-NDI-Si7 and Si23-NDI-Si23 that selfassemble into $\mathrm{Col}_{\mathrm{ob}}$ morphologies. The block molecules of family 2 showed typical reflections of a lamellar organization (LAM), instead, which is in agreement with the benzylprotected UPy-ODMS system. ${ }^{46}$

The structural variations throughout both families of conjugates result in two persistent trends, regardless of molecular architecture: the extension of the NDI block by one unit increases $L_{0}$ by approximately $0.7-0.9 \mathrm{~nm}$, while the addition of 8 ODMS units increases $L_{0}$ by approximately $1.1-$ $1.3 \mathrm{~nm}$ (Table 2 and Table $\mathrm{S} 1$ ). The same increase in $L_{0}$ of approximately $1.3 \mathrm{~nm}$ was also observed in the LAM morphologies of benzyl protected UPy-ODMS block molecules upon extending the siloxane block by 8 repeating units. ${ }^{46}$ The consistency of generated morphologies within the same molecular architecture, combined to the approximately linear variations of $L_{0}$ upon structural changes completely rule out a block copolymeric self-assembly behavior for both family $\mathbf{1}$ and family 2 . They highly support a conformationally disordered crystalline self-assembly, ${ }^{29-33}$ where domain spacing scales linearly with molecular size and intermolecular interactions govern the self-assembly process. As such, BCP theory ${ }^{19-21}$ cannot be used to rationalize/predict the morphologies into which the NDI-ODMS conjugates self-assemble, because they are controlled by the strength and directionality of intermolecular interactions between crystalline moieties rather than minimization of interfacial energy at a given volume fraction. The absence of mobility and the strong long-range order witnessed by the numerous sharp reflections in the MAXS profiles agree with the definition of the NDI-ODMS conjugates as conformationally disordered crystals, rather than liquid crystals.

Once established the influence of molecular architecture on the bulk morphologies, we investigated the packing of the NDIs within the NDI-ODMS block molecules. For this purpose Xray quality crystals of $\mathbf{5}$ (synthesis in SI) were obtained from slow vapor diffusion of hexane (antisolvent) into a 1,2dichloroethane solution. The compound crystallizes in an orthorhombic lattice with eight molecules in the unit cell. By $\pi-\pi$ stacking the molecules are arranged in a cofacial, twisted fashion (Figure 4a and 4b; SI pages S115-S116). The preorganization of $\mathbf{5}$ in the crystal for the formation of emissive aggregated species is evident. Hence, upon excitation $\left(\lambda_{\text {exc }}=365\right.$ $\mathrm{nm}) \mathbf{5}$ shows the typical blue-green luminescence (Figure 4c; Figures S115-S116) of NDIs observed in other bulk systems. ${ }^{57}$ The same luminescence is observed on drop cast films of 5: a broad, structureless emission band centered at $490 \mathrm{~nm}$ (bluegreen) is visible in the fluorescence spectrum (Figure $4 \mathrm{~g}$ ). A very similar luminescence is observed with Si15-NDI-Si15 (Figure 4d and 4h; Figure S116) and Si15-NDI 2 -Si15 (Figure S115), suggesting somewhat similar interactions between NDI units in the columnar morphologies of family 1, despite some clear differences in the UV-vis spectra (Figures S121-S123). The luminescence of Sil5-NDI-Si15 and Si15-NDI - -Si15 contrasts starkly with that of NDI-Si8-NDI (Figure 4e and 4i) and $\mathbf{N D I}_{2}-\mathbf{S i 8}-\mathrm{NDI}_{2}$ (Figure S120), characterized by two resolved vibronic bands centered at 460 and $490 \mathrm{~nm}$ like reference NDIs 1 (Figure $4 \mathrm{f}$ and $4 \mathrm{j}$ ) and 3 (Figure S119). The emission spectra of such compounds are the mirror images of their absorption (Figures S117-S120). This suggests no interactions between the transition dipole moments of the NDIs of family 2, which ultimately results in monomeric emissions. $^{47}$

The macroscopic and microscopic observations of the waxy block molecules are in line with their definition as conformationally disordered crystals. Both families of compounds present a "conformationally disordered" character thanks to the ODMS that impart disorder through their conformational flexibility, while the intermolecular interactions between NDI cores impose order and select the morphology through a crystallization process. As such, severe rules control the packing of the NDIs, and consequently the long-range order of the conjugates. This molecular picture is also suggested by a number of mixing experiments carried out (Table 3 and Figure $4 \mathrm{k}$ and 41). Block molecules were mixed in different molar ratios and by varying the length of the ODMS and NDI blocks individually or simultaneously. Birefringence of the mixed samples was always observed with POM, indicating long-range order also in this case (Figure S124).

The key parameter in the long-range order of the block molecules is the number of NDI units in the hard block, as revealed by the MAXS patterns (Figure $4 \mathrm{k}$ and 41; Figures S125-S131). New lattices with intermediate domain spacings are generated when compounds with the same number of aromatic cores in the hard block but different ODMS lengths are mixed, thus giving the opportunity to easily tune the periodicity (Table 3 and Figure $4 \mathrm{k}$ ). Surprisingly enough, this effect is also observed when molecules of different families are mixed. Such experiments also highlighted a composition dependent preference for the LAM morphology (Figures S129-S131). In stark contrast, macrophase separation is observed any time the packing rule of the number of NDIs is not respected, with the MAXS profiles showing reflections of two self-sorting lattices (Figure 41). These results highlight the synergy between thermodynamic incompatibility and crystallization in directing the self-assembly of the block molecules. In the absence of crystallization, the NDI blocks of NDI-ODMS conjugates with different number of NDIs would simply collapse and merge due to immiscibility with the ODMS block. 
a)

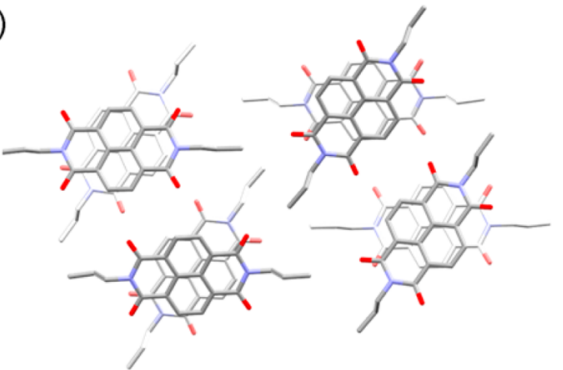

c)

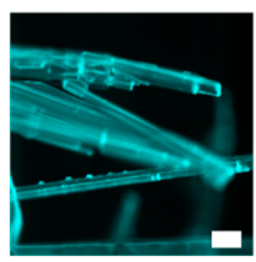

g)

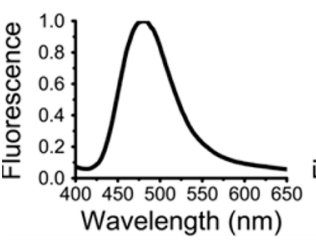

h)
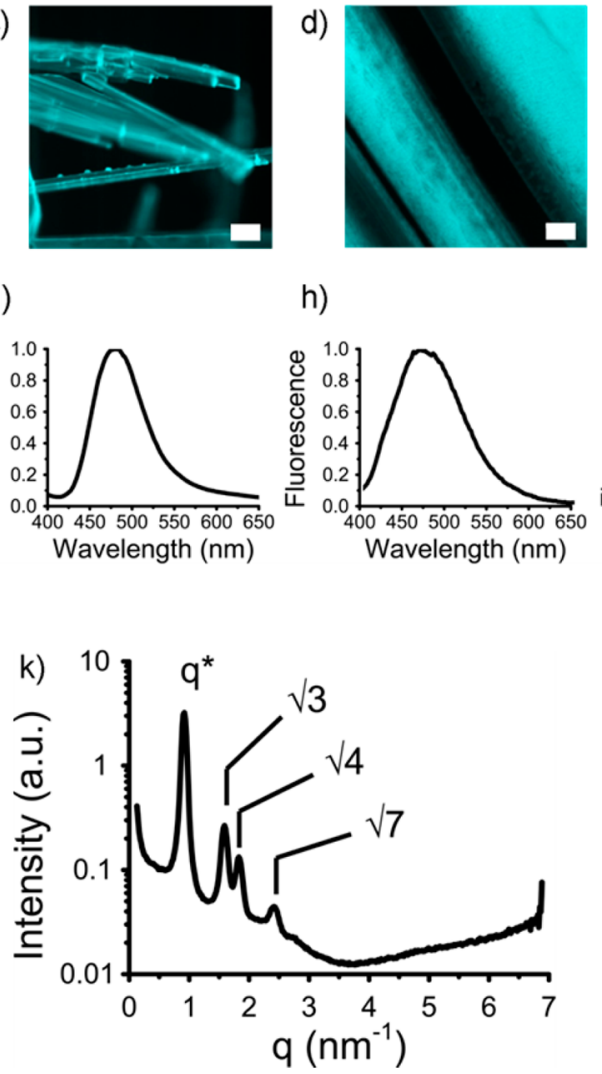

b)
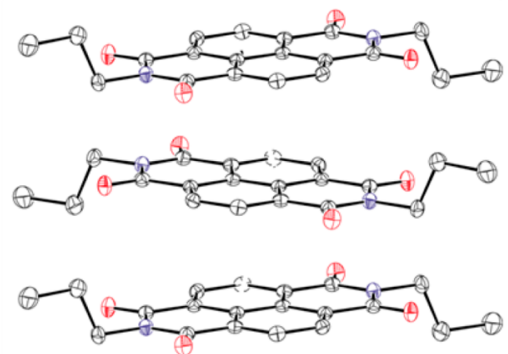

e)

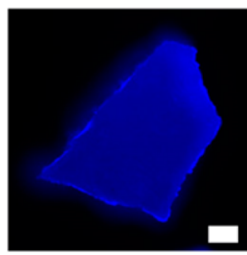

f)

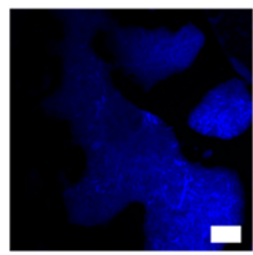

i)

j)
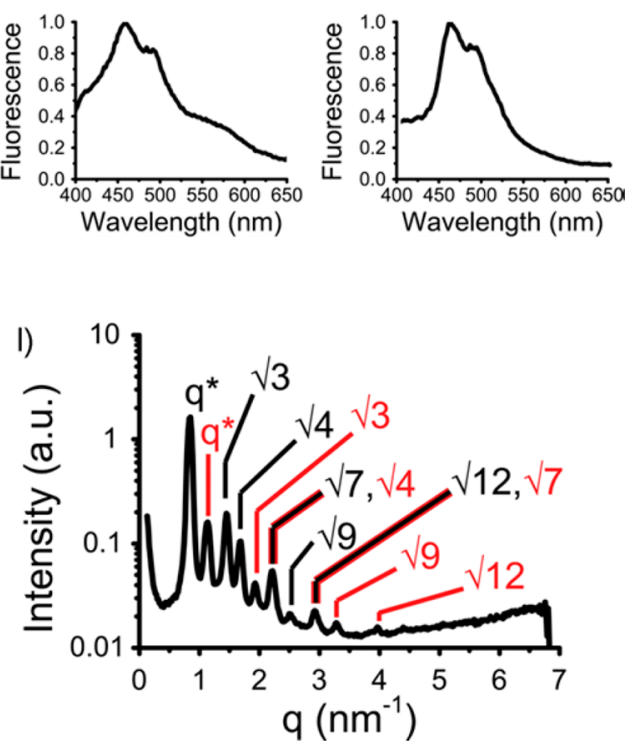

Figure 4. (a) View of the unit cell of 5 along the $a$-axis. (b) Packing of 5 in the crystal viewed along the $b$-axis. Displacement ellipsoids are drawn at the $50 \%$ probability level. Carbon atoms are depicted in gray, oxygen atoms in red and nitrogen atoms in violet. Hydrogen atoms are omitted for clarity. Fluorescence microscopy micrographs of (c) crystals of 5, (d) Si15-NDI-Si15, (e) NDI-Si8-NDI, and (f) 1 (artificial colors; excitation range $340-380 \mathrm{~nm}$, scale bars $100 \mu \mathrm{m}$ ). Normalized fluorescence spectra of drop cast films on glass of (g) 5, (h) Si15-NDI-Si15, (i)

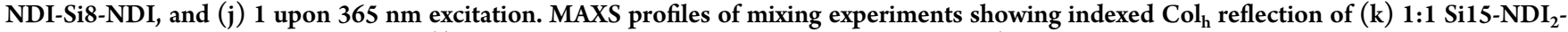
Si15 and Si23-NDI ${ }_{2}$-Si23 mixture and (1) 1:1 Si23-NDI ${ }_{2}$-Si23 and Si15-NDI-Si15 mixture (black labels for Si23-NDI ${ }_{2}-S_{2} 23$, red labels for Si15NDI-Si15). Intensity is given in arbitrary units.

Table 3. NDI-ODMS Mixing Experiments with Molar Ratios $\left(n_{\mathrm{A}}: n_{\mathrm{B}}\right)$, Observed Morphologies (Phase) and Related Domain Spacings $\left(L_{0}\right)$

\begin{tabular}{|c|c|c|c|c|}
\hline compound A & compound B & $n_{\mathrm{A}}: n_{\mathrm{B}}$ & phase(s) & $L_{0}(\mathrm{~nm})^{a}$ \\
\hline Si15-NDI ${ }_{2}-\mathrm{Si} 15$ & $\mathrm{Si} 23-\mathrm{NDI}_{2}-\mathrm{Si} 23$ & $1: 1$ & $\mathrm{Col}_{\mathrm{h}}$ & 7.9 \\
\hline Si15-NDI-Si15 & Si15-NDI ${ }_{2}-\mathrm{Si} 15$ & $1: 1$ & $2 \mathrm{Col}_{\mathrm{h}}$ lattices & $6.5,7.6^{b}$ \\
\hline $\mathrm{Si} 23-\mathrm{NDI}_{2}-\mathrm{Si} 23$ & Si15-NDI-Si15 & $1: 1$ & $2 \mathrm{Col}_{\mathrm{h}}$ lattices & $8.6,6.5^{b}$ \\
\hline NDI-Si8-NDI & $\mathrm{NDI}_{2}-\mathrm{Si} 24-\mathrm{NDI}_{2}$ & $1: 1$ & 2 LAM lattices & $4.4,7.4^{b}$ \\
\hline Si15-NDI-Si15 & NDI-Si24-NDI & $1: 1$ & LAM & 6.8 \\
\hline Si15-NDI-Si15 & NDI-Si24-NDI & $1: 4$ & LAM & 6.6 \\
\hline Si15-NDI-Si15 & NDI-Si24-NDI & $4: 1$ & $\begin{array}{c}\mathrm{Col}_{\mathrm{h}} \text { and } \\
\mathrm{LAM}^{b}\end{array}$ & $6.5,6.9^{b}$ \\
\hline
\end{tabular}

${ }^{a} L_{0}$ is the lattice parameter in $\mathrm{Col}_{\mathrm{h}}$ and the bilayer thickness in LAM. ${ }^{b}$ First and second value/abbreviation refers to compound $\mathrm{A}$ and $\mathrm{B}$, respectively.
This phenomenon has never been observed with the previously reported ODMS-based block molecules, either because no modularity was explored in the design of the crystalline block $^{46,52}$ or the system simply followed BCP theory. ${ }^{27}$

Finally, we highlight the use of DSC as an additional technique to infer the outcome of the mixing experiments in which molecular architecture is preserved: one transition only, occurring at an intermediate temperature between those of the individual compounds, is measured upon heating and cooling in this case (Figure S132).

Hypothetical Packing Models. By merging all the information presented so far we can hypothesize packing models for both columnar and lamellar morphologies (Figure $5 \mathrm{a}$ and $5 \mathrm{~b}$ ). Phase separation between alkyl chains and ODMS is assumed for both architectures and it is corroborated by previous literature for even lower molar mass systems. ${ }^{58}$ Only 


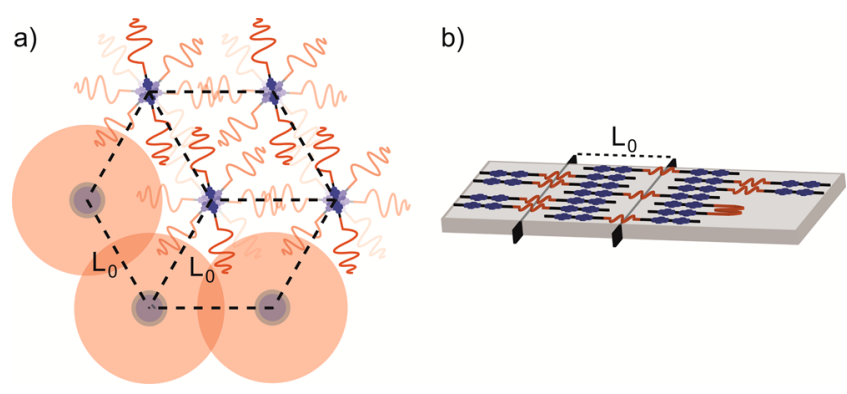

Figure 5. Hypothetical packing models of (a) $\mathrm{Col}_{h}$ and (b) LAM morphologies. Respective domain spacings $\left(L_{0}\right)$ are also shown.

packing models for $\mathrm{Col}_{\mathrm{h}}$ and LAM morphologies will be described here, while that of the two $\mathrm{Col}_{\mathrm{ob}}$ molecules can be found in SI (Figure S100 and S104). The volumes of the unit cells of the columnar morphologies were defined from the exact 2D-morphologies obtained from the MAXS profiles and the inter disc spacing of $0.42 \mathrm{~nm}$ (third dimension of the unit cell) consistently observed in the Wide Angle X-ray Scattering (WAXS) measurements of the block molecules of family 1 (WAXS profiles at SI pages S102-S113 and unit cell determination at SI page S131). In addition to the highly ordered nanostructure morphology observed in MAXS, the presence of an inter disc spacing peak in the WAXS profiles of the NDI-ODMS conjugates of family 1 confirms that the center of mass of these block molecules lies on crystalline lattices. The number of molecules per unit cell was calculated by comparing the volume of the unit cell with the molecular volume of the block molecules, which was estimated from density considerations and molar mass values (SI page S131). In the lamellar morphologies, the unit cell is represented by a single molecule due to the layered structure.

According to the combination of MAXS and WAXS the number of molecules to accommodate in the unit cell of the $\mathrm{Col}_{\mathrm{h}}$ morphologies is four. The high resemblance of the fluorescence signatures of the block molecules of family $\mathbf{1}$ and 5 supports very similar, cofacial $\pi-\pi$ stacking interactions between the NDIs. Hence, it is very likely that the stacking of the NDIs in the $\mathrm{Col}_{\mathrm{h}}$ morphologies occurs with a fixed angle like in the crystals of $\mathbf{5}$, in which columns of infinite length are obtained with this structural requisite (Figure $4 \mathrm{~b}$ ). An indirect proof of this conclusion derives from the fact that random stacking angles would result in a unit cell composed of only one molecule, rather than four. Positioning the molecules into the unit cell leads to many possibilities and we speculate that the conjugates of family 1 are arranged with a molecule in each vertex of the $2 \mathrm{D}$ hexagonal lattice of length $L_{0}$. Intermolecular interactions $(\pi-\pi$ stacking) between NDIs bring to the formation of the columnar structures, while the ODMS fill the volume between the columns. Finally, the approximate increase of 1.1-1.3 nm in $L_{0}$ upon extending the ODMS of 8 units in both family $\mathbf{1}$ and family $\mathbf{2}$ highly supports the interdigitation between the siloxane block. Such extension consists in 16 units overall in family $\mathbf{1}$ and 8 in family 2 and it would result in a double increase of $L_{0}$ in family 1 in the absence of interdigitation. A pictorial representation of the packing model of the $\mathrm{Col}_{\mathrm{h}}$ morphologies is shown in Figure 5a.

The packing model of the LAM morphologies of family $\mathbf{2}$ is schematically depicted in Figure $5 \mathrm{~b}$. The monomeric emission recorded for this series of block molecules suggests no interactions between the aromatic clouds of the NDIs as already reported for slipped stacks of NDIs in bulk. ${ }^{48}$ This allows us to focus on the cross section of the lamellar structure, in which the NDIs are parallel to each other, in line with the anisotropy observed with POM. The previously discussed constant increase of $L_{0}$ on structural variations highly supports end-group interdigitation also for the LAM morphologies. A non interdigitated packing model may also be hypothesized, but it would result in a double increase of $L_{0}$ upon extending the NDI block by one unit (Figure S133). Furthermore, interdigitation allows the presence of a number of different conformations of the molecules, including plausible bent architectures necessarily absent in the noninterdigitated packing model.

\section{CONCLUSIONS}

In conclusion, we have reported the self-assembly behavior in bulk of two families of block molecules consisting of naphthalenediimides and oligodimethylsiloxanes. We show that a synergy of thermodynamic incompatibility between NDIs and ODMS and crystallization of the NDIs causes the moieties to nanophase separate in bulk, giving access to two distinct morphologies with sub-10 $\mathrm{nm}$ periodicities and a conformationally disordered crystalline self-assembly behavior. The high crystallinity of the NDI cores in the block molecules is indicated by their fluorescence signatures and the intensity of the transitions measured with DSC. An unambiguous indication of the pivotal role played by the crystallization process was obtained from the mixing experiments, in which packing constraints only allow efficient mixing of block molecules with the same number of NDI units. The periodicity of the new lattices can be finely tuned by simply observing this structural constraint. Macrophase separation is observed whenever such consitutional bias is not respected.

Our ODMS-based conformationally disordered crystals possess strong long-range order, couple two moieties with high etch contrast and do not easily undergo structural rearrangements thanks to their low mobility, a problem often encountered with liquid crystals. In this sense, ODMS-based conformationally disordered crystals match all the requisites of high $\chi$ /low $N$ block copolymers, with the additional advantage of the high definition of small organic molecules. Analogously to $\chi, N$ and $f$ in block copolymers, molecular design, molecular size and mixing compounds allow morphology selection and fine-tuning of the periodicity in conformationally disordered crystals. We are currently exploring the functionalization of surfaces with our NDI-ODMS conjugates and their structural analogues, and results will be reported in due time. As a final remark, we speculate that ODMS functionalization of flat, crystalline organic moieties may represent a plausible strategy for the obtainment of crystalline sheets.

\section{MATERIALS AND METHODS}

Unless stated otherwise, all reagents and chemicals were obtained from commercial sources (TCI Chemicals and Sigma-Aldrich) at the highest purity available and used without further purification. Pt-catalyst HS 432 used in hydrosilylations was purchased from Umicore. All solvents were of AR quality and purchased from Biosolve. Flash chromatography was performed on a Grace Reveleris flash chromatography system using Reveleris Silica Flash Cartridges. Reactions were followed by thin-layer chromatography (precoated $0.25 \mathrm{~mm}, 60-\mathrm{F} 254$ silica gel plates from Merck).

Samples for polarized optical microscopy and fluorescence microscopy imaging were deposited on glass coverslips, heated up 
above the isotropic melt and slowly cooled down $\left(10^{\circ} \mathrm{C} / \mathrm{min}\right)$ prior to measure.

Solution UV-vis measurements were performed using quartz cuvettes with $1 \mathrm{~cm}$ optical path.

Samples for MAXS and WAXS were mounted on V1 grade mica sheets 5-7 $\mu \mathrm{m}$ thick. The mica plates were deposited on glass coverslips, heated up above the isotropic melt and slowly cooled down $\left(10^{\circ} \mathrm{C} / \mathrm{min}\right)$ until the observation of birefrigence with POM. Samples of those compounds that do not possess thermal transitions up to 250 ${ }^{\circ} \mathrm{C}$ were prepared by deposition of the glass coverslips on hot plates at $300{ }^{\circ} \mathrm{C}$ for $30 \mathrm{~min}$ prior to measure.

Glass substrates for UV-vis and Fluorescence measurements of drop cast films were prepared by $10 \mathrm{~min}$ sonication in AR grade acetone, SodiumDodecylSulfate (SDS) solution in Milli- $\mathrm{Q}$ water and, finally, AR grade i-propanol. $5 \times 10^{-3} \mathrm{M} \mathrm{CHCl}_{3}$ solutions of the desired molecules were then drop cast on such cleaned and dried glass substrates. The solvent was removed and the drop cast films were annealed by heating up above the isotropic melt and slowly cooling down $\left(10^{\circ} \mathrm{C} / \mathrm{min}\right)$.

$\mathrm{X}$-ray quality crystals of $\mathbf{5}$ were obtained by slow diffusion of hexane (antisolvent) into a saturated solution of 5 in 1,2-dichloroethane. The saturated 1,2-dichloroethane solution was prepared by trying to dissolve $30 \mathrm{mg}$ of 5 in $2 \mathrm{~mL}$ of solvent and subsequently filtering off the undissolved particles with a $0.2 \mu \mathrm{m}$ Whatman Anatop 10 filter.

Mixing experiments were carried out by combining solutions of molecules separately dissolved in $\mathrm{CHCl}_{3}$, allowing samples to dry overnight, and annealing them by slow cooling from the isotopropic melt.

\section{ASSOCIATED CONTENT}

\section{S Supporting Information}

The Supporting Information is available free of charge on the ACS Publications website at DOI: 10.1021/acsnano.6b08380.

Synthethic procedures and characterization including ${ }^{1} \mathrm{H}$ NMR, ${ }^{13} \mathrm{C}$ NMR, FT-IR and MALDI-TOF-MS spectra of all new synthesized compounds; Bulk characterization of the NDI-ODMS conjugates with DSC, POM, Fluorescence Microscopy, MAXS and WAXS; X-ray crystallographic data of 5; Formulation of the hypothetical packing models (PDF)

\section{AUTHOR INFORMATION}

\section{Corresponding Author}

*E-mail: e.w.meijer@tue.nl.

\section{ORCID $\odot$}

E. W. Meijer: 0000-0003-4126-7492

\section{Notes}

The authors declare no competing financial interest.

\section{ACKNOWLEDGMENTS}

The authors would like to thank the Dutch Ministry of Education, Culture and Science (Gravity program 024.001.035) and The Netherlands Organisation for Scientific Research (NWO TOP-PUNT 718.014.003) for financial support. The authors acknowledge Dr. Miguel García-Iglesias for intellectual discussions, Mr. Ronald P. J. Gosens for synthetic assistance, Prof. Ilja Voets for the use of the SAXS instrument, Dr. Neus Vilanova-García for fluorescence microscopy imaging and $\mathrm{Mr}$. Ralf Bovee for MALDI-TOF-MS measurements. The X-ray diffractometer was financed by The Netherlands Organisation for Scientific Research (NWO).

\section{REFERENCES}

(1) Whitesides, G. M.; Boncheva, M. Beyond Molecules: SelfAssembly of Mesoscopic and Macroscopic Components. Proc. Natl. Acad. Sci. U. S. A. 2002, 99, 4769.

(2) Gates, B. D.; Xu, Q.; Stewart, M.; Ryan, D.; Willson, C. G.; Whitesides, G. M. New Approaches to Nanofabrication: Molding, Printing, and Other Techniques. Chem. Rev. 2005, 105, 1171.

(3) Whitesides, G. M. Nanoscience, Nanotechnology, and Chemistry. Small 2005, 1, 172.

(4) Palermo, V.; Samorì, P. Molecular Self-Assembly Across Multiple Length Scales. Angew. Chem., Int. Ed. 2007, 46, 4428.

(5) Qin, L.; Lv, K.; Shen, Z.; Liu, M. Self-Assembly of Organic Molecules into Nanostructures. In Soft Matter Nanotechnology: From Structure to Function; Chen, X., Fuchs, H., Eds.; Wiley-VCH Verlag GmbH \& Co. KgaA: Weinheim, Germany, 2015.

(6) Lundstrom, M. Moore's Law Forever? Science 2003, 299, 210211

(7) Waldrop, M. M. The Chips Are Down for Moore's Law. Nature 2016, 530, 144-147.

(8) Tschierske, C. Non-Conventional Liquid Crystals - the Importance of Micro-Segregation for Self-Organisation. J. Mater. Chem. 1998, 8, 1485.

(9) Kim, H. J.; Kim, T.; Lee, M. Responsive Nanostructures from Aqueous Assembly of Rigid-Flexible Block Molecules. Acc. Chem. Res. 2011, 44, 72 .

(10) Kato, T. Self-Assembly of Phase-Segregated Liquid Crystal Structures. Science 2002, 295, 2414.

(11) Lazzari, M.; Arturo López-Quintela, M. Block Copolymers As a Tool for Nanomaterial Fabrication. Adv. Mater. 2003, 15, 1583.

(12) Hamley, I. W. Developments in Block Copolymer Science and Technology. Mater. Today 2004, 7, 53.

(13) Cheng, J. Y.; Ross, C. A.; Smith, H. I.; Thomas, E. L. Templated Self-Assembly of Block Copolymers: Top-Down Helps Bottom-Up. Adv. Mater. 2006, 18, 2505.

(14) Bates, C. M.; Maher, M. J.; Janes, D. W.; Ellison, C. J.; Willson, C. G. Block Copolymer Lithography. Macromolecules 2014, 47, 2-12.

(15) Handbook of Liquid Crystals, 2nd ed.; Goodby, J. W., Collings, P. J., Kato, T., Tschierske, C., Gleeson, H., Raynes, P., Eds.; Wiley VCH, 2014.

(16) Tschierske, C. Development of Structural Complexity by Liquid-Crystal Self-Assembly. Angew. Chem., Int. Ed. 2013, 52, 88288878.

(17) Mai, S.; Fairclough, J. P. A.; Terrill, N. J.; Turner, S. C.; Hamley, I. W.; Matsen, M. W.; Ryan, A. J.; Booth, C. Microphase Separation in Poly(oxyethylene)-Poly(oxybutylene) Diblock Copolymers. Macromolecules 1998, 31, 8110.

(18) Khandpur, A. K.; Foerster, S.; Bates, F. S.; Hamley, I. W.; Ryan, A. J.; Bras, W.; Almdal, K.; Mortensen, K. Polyisoprene-Polystyrene Diblock Copolymer Phase Diagram near the Order-Disorder Transition. Macromolecules 1995, 28, 8796.

(19) Cochran, E. W.; Garcia-Cervera, C. J.; Fredrickson, G. H. Stability of the Gyroid Phase in Diblock Copolymers at Strong Segregation. Macromolecules 2006, 39, 2449.

(20) Bates, F. S.; Fredrickson, G. H. Block Copolymer Thermodynamics: Theory and Experiment. Annu. Rev. Phys. Chem. 1990, 41, 525-557.

(21) Leiblert, L. Theory of Microphase Separation in Block Copolymers. Macromolecules 1980, 13, 1602-1617.

(22) Sinturel, C.; Bates, F. S.; Hillmyer, M. A. High $\chi$-Low N Block Polymers: How Far Can We Go? ACS Macro Lett. 2015, 4, 10441050.

(23) Voet, V. S. D.; Pick, T. E.; Park, S. M.; Moritz, M.; Hammack, A. T.; Urban, J. J.; Ogletree, D. F.; Olynick, D. L.; Helms, B. A. Interface Segregating Fluoralkyl-Modified Polymers for High-Fidelity Block Copolymer Nanoimprint Lithography. J. Am. Chem. Soc. 2011, 133, 2812.

(24) Pitet, L. M.; van Loon, A. H. M.; Kramer, E. J.; Hawker, C. J.; Meijer, E. W. Nanostructured Supramolecular Block Copolymers 
Based on Polydimethylsiloxane and Polylactide. ACS Macro Lett. 2013, 2, 1006.

(25) Nunns, A.; Gwyther, J.; Manners, I. Inorganic Block Copolymer Lithography. Polymer 2013, 54, 1269-1284.

(26) Pitet, L. M.; Wuister, S. F.; Peeters, E.; Kramer, E. J.; Hawker, C. J.; Meijer, E. W. Well-Organized Dense Arrays of Nanodomains in This Films of Poly(dimethylsiloxane)-b-Poly(Lactide) Diblock Copolymers. Macromolecules 2013, 46, 8289.

(27) Van Genabeek, B.; De Waal, B. F. M.; Gosens, M. M. J.; Pitet, L. M.; Palmans, A. R. A.; Meijer, E. W. Synthesis and Self-Assembly of Discrete Dimethylsiloxane-Lactid Acid Diblock Co-Oligomers: the Dononacontamer and Its Shorter Homologues. J. Am. Chem. Soc. 2016, 138, 4210.

(28) Imrie, C. T.; Henderson, P. A. Liquid Crystal Dimers and Higher Oligomers: Between Monomers and Polymers. Curr. Opin. Colloid Interface Sci. 2002, 7, 298.

(29) Timmermans, J. Plastic Crystals: a Historical Review. J. Phys. Chem. Solids 1961, 18, 1-8.

(30) Angell, C. A. Relaxation in Liquids, Polymers and Plastic Crystals - Strong/Fragile Patterns and Problems. J. Non-Cryst. Solids 1991, 13, 131-133.

(31) Pringle, J. M.; Howlett, P. C.; MacFarlane, D. R.; Forsyth, M. Organic Ionic Plastic Crystals: Recent Advances. J. Mater. Chem. 2010, 20, 2056.

(32) Wunderlich, B.; Grebowicz, J. Thermotropic Mesophases and Mesophase Transitions of Linear, Flexible Macromolecules. In Liquid Crystal Polymers II/III. Advances in Polymer Science; Platé, N. A., Ed.; Springer: Berlin, Heidelberg, 1984; Vol 60/61.

(33) Chen, W.; Wunderlich, B. Nanophase Separation of Small and Large Molecules. Macromol. Chem. Phys. 1999, 200, 283-311.

(34) Sergeyev, S.; Pisula, W.; Geerts, Y. H. Discotics Liquid Crystals; a New Generation of Organic Semiconductors. Chem. Soc. Rev. 2007, 36, 1902.

(35) Kato, T.; Yasuda, T.; Kamikawa, Y.; Yoshio, M. Self-Assembly of Functional Columnar Liquid Crystals. Chem. Commun. 2009, 7, 729.

(36) Tschierske, C. Liquid Crystal Engineering - New Complex Mesophase Structures and Their Relations to Polymer Morphologies, Nanoscale Patterning and Crystal Engineering. Chem. Soc. Rev. 2007, 36, 1930.

(37) IUPAC. Compendium of Chemical Terminology, 2nd ed. (the "Gold Book"); McNaught, A. D., Wilkinson, A., Eds.; Blackwell Scientific Publications: Oxford, 1997.

(38) Jenekhe, S. A.; Chen, X. L. Self-Assembled Aggregates of RodCoil Block Copolymers and Their Solubilization and Encapsulation of Fullerenes. Science 1998, 279, 1903-190.

(39) Jenekhe, S. A.; Chen, X. L. Self-Assembly of Ordered Microporous Materials from Rod-Coil Block Copolymers. Science 1999, 283, 372-375.

(40) Lee, M.; Cho, B.-K.; Zin, W.-C. Supramolecular Structures from Rod-Coil Block Copolymers. Chem. Rev. 2001, 101, 3869-3892.

(41) Cheng, X. H.; Diele, S.; Tschierske, C. Molecular Design of Liquid-Crystalline Block Molecules: Semifluorinated Pentaerythritol Tetrabenzoates Exhibiting Lamellar, Columnar, and Cubic Mesophases. Angew. Chem., Int. Ed. 2000, 39, 592.

(42) Kölbel, M.; Beyersdorff, T.; Sletvold, I.; Tschierske, C.; Kain, J.; Diele, S. Design of New Mesogenic Block Molecules: Formation of Columnar Mesophases by Calamitic Bolaamphiphiles with Lateral Lipophilic Substituents. Angew. Chem., Int. Ed. 1999, 38, 1077.

(43) Reddy, R. A.; Dantlgraber, G.; Baumeister, U.; Tschierske, C. Liquid-Crystalline Quaternary Block Molecules Incorporating BentCore Units. Angew. Chem., Int. Ed. 2006, 45, 1928.

(44) Hayakawa, T.; Goseki, R.; Kakimoto, M. A.; Tokita, M.; Watanabe, J.; Liao, Y.; Horiuchi, S. Self-Assembled Lamellar Nanostructures of Wholly Aromatic Rod-Rod-Type Block Molecules. Org. Lett. 2006, 8, 5453.

(45) Gehringer, L.; Bourgogne, C.; Guillon, D.; Donnio, B. LiquidCrystalline Octopus Dendrimers: Block Molecules with Unusual Mesophase Morphologies. J. Am. Chem. Soc. 2004, 126, 3856.
(46) Zha, R. H.; de Waal, B.; Lutz, M.; Teunissen, A. J. P.; Meijer, E. W. Endgroups of Functionalized Siloxane Oligomers Direct Block Copolymeric or Liquid Crystalline Self-Assembly Behavior. J. Am. Chem. Soc. 2016, 138, 5693-5698.

(47) Bhosale, S. V.; Jani, C. H.; Langford, S. J. Chemistry of Naphthalene Diimides. Chem. Soc. Rev. 2008, 37, 331.

(48) Pandeeswar, M.; Khare, H.; Ramakumar, S.; Govindaraju, T. Biomimetic Molecular Organization of Naphthalene Diimide in the Solid State: Tunable (Chiro-) Optical, Viscoelastic and Nanoscale Properties. RSC Adv. 2014, 4, 20154.

(49) Ganesan, P.; van Lagen, B.; Marcelis, A. T. M.; Sudhŏlter, E. J. R.; Zuilhof, H. Siloxanes with Pendent Naphthalene Diimides: Synthesis and Fluorescence Quenching. Org. Lett. 2007, 9, 22972300.

(50) Clarke, D.; Mathew, S.; Matisons, J.; Simon, G.; Skelton, B. W. Synthesis and Characterization of a Range of POSS Imides. Dyes Pigm. 2012, 92, 659-667.

(51) Littlejohn, S.; Nogaret, A.; Prentice, G. M.; Dan Pantos, G. Pressure Sensing and Electronic Amplification with Functionalized Graphite-Silicone Composite. Adv. Funct. Mater. 2013, 23, 53985402.

(52) Nickmans, K.; Murphy, J. N.; Waal, B.; De Leclère, P.; Doise, J.; Gronheid, R.; Broer, D. J.; Schenning, A. P. H. J. Sub-5 nm Patterning by Directed Self-Assembly of Oligo (Dimethylsiloxane) Liquid Crystal Thin Films. Adv. Mater. 2016, 26, 10068-10072.

(53) Galvin, C. J.; Bain, E. D.; Henke, A.; Genzer, J. Instability of Surface-Grafted Weak Polyacid Brushes on Flat Substrates. Macromolecules 2015, 48, 5677.

(54) Tambara, K.; Ponnuswamy, N.; Hennrich, G.; Pantoş, G. D. Microwave-Assisted Synthesis of Naphthalenemonoimides and NDesymmetrized Naphthalenediimides. J. Org. Chem. 2011, 76, 33383347.

(55) Markó, I. E.; Stérin, S.; Buisine, O.; Mignani, G.; Branlard, P.; Tinant, B.; Declercq, J.-P. Selective and Efficient Platinum(0)-Carbene Complexes As Hydrosilylation Catalysts. Science 2002, 298, 204-206.

(56) Höhne, G. W. H.; Hemminger, W. F.; Flammersheim, H.-J. Differential Scanning Calorimetry, 2nd ed.; Springer-Verlag Berlin Heidelberg GmbH, 2003.

(57) Bell, T. D. M.; Bhosale, S. V.; Forsyth, C. M.; Hayne, D.; Ghiggino, K. P.; Hutchison, J. a; Jani, C. H.; Langford, S. J.; Lee, M. AP.; Woodward, C. P. Melt-Induced Fluorescent Signature in a Simple Naphthalenediimide. Chem. Commun. 2010, 46, 4881.

(58) García-Iglesias, M.; de Waal, B. F. M.; de Feijter, I.; Palmans, A. R. A.; Meijer, E. W. Nanopatterned Superlattices in Self-Assembled $\mathrm{C}_{2}$ -Symmetric Oligodimethylsiloxane-Based Benzene-1,3,5-Tricarboxamides. Chem. - Eur. J. 2015, 21, 377-385.

(59) The choice of either plastic crystals (PCs) or conformationally disordered crystals (CDCs) to categorize the NDI-ODMS block molecules is complicated by the lack of official definitions from IUPAC and falls outside the scope of our investigation. In this article we focus on understanding the driving forces that control the self-assembly of the NDI-ODMS conjugates. However, for the sake of clarity, from now on we will refer to our structures as CDCs. 